\title{
A Semiótica do Design: A Construção da Identidade nos Jovens do Hip Hop no Viaduto de Santa Tereza
}

Clara Santana Lins Cerqueira;

Rita Aparecida da Conceição Ribeiro;

\section{resumo:}

O presente estudo teve como objetivo investigar os aspectos simbólicos do design e suas influências inseridas na cultura urbana do hip hop. Analisar como esses jovens, em sua maioria, negros de classe média baixa, lançam mão de artigos da indústria para se auto afirmarem perante a sociedade e fortalecer suas identidades. Desse modo, fez-se necessário um estudo mais aprofundado em manifestações socioculturais como as culturas urbanas, a identidade juvenil, formas de ocupação da cidade, pesquisas acerca da cultura black music e o seu surgimento. Entender como o design pode ser uma ferramenta poderosa na transmissão e na promoção de manifestos culturais. Trazer uma reflexão de como os indivíduos se apropriam dos espaços e dos objetos e como esses fazem parte deles e de sua existência sociocultural. O objeto de estudo para essa pesquisa foi o manifesto do coletivo Família de Rua. A Família de Rua é um grupo de jovens rappers que promovem encontros aos domingos a tarde no Viaduto de Santa Tereza, em Belo Horizonte. Proporcionam interação, lazer e promoção cultural para jovens, em sua maioria da periferia. Através das músicas de protesto e de cunho político, intencionam discussões enriquecedoras para os jovens presentes. Também foram feitas entrevistas com participantes do movimento para que pudéssemos ter uma visão global do movimento e o verdadeiro significado da música, e dos símbolos estéticos e que permeiam o movimento na vida desses jovens.

palavras-chave:

design; hip hop; culturas urbanas. 


\section{Introdução}

O presente estudo tem como foco a semiótica do Design inserida na cultura do Hip Hop, tendo como seu maior público os jovens. Atualmente esse público se apropria das dimensões simbólicas como forma de expressar suas identidades culturais e, mais que isso, como forma de comunicação.

Nos anos 50 a música invade "a cena" e se torna o maior vinculador de identidade e valores. Até então, não existia uma cultura juvenil, através da qual os jovens construíam sua própria forma de pensar, agir, vestir-se e se expressar, de um modo geral. A música, através dos discursos que nela estão veiculados, instigou a busca por uma identidade autêntica, autônoma, quebrando paradigmas e se desvinculando, aos poucos, da maneira de ser "adulto". A juventude encontra o verdadeiro modo de ser jovem criando sua própria identidade e seu próprio estilo de vida.

Esta identidade faz-se visível pela apropriação de elementos materiais, imateriais e valores simbólicos contidos neles. O modo como os jovens se apropriam do espaço urbano criando suas tribos é uma forma de autoafirmação e expressão, na maioria das vezes, de seus infortúnios ligados à sua vida social. O design vem como uma ferramenta que, através do mercado de produtos e do ambiente urbano, contribui para a ressignificação da maneira de ser do jovem ou de se fazer parte de alguma tribo urbana.

A cultura do hip hop, a partir dos anos 80 , foi o caminho encontrado então para a formação de identidade de um grupo marginalizado, que acabou se transformando na linguagem de protesto de diversos jovens por todo o mundo. Assim também é no Brasil e em Belo Horizonte. Nossa proposta de estudo privilegia o grupo que se reúne aos Domingos no Viaduto de Santa Tereza, fomentado pelo coletivo Familia de Rua.

O Hip Hop no Viaduto de Santa Tereza, composto por um público em sua maioria jovem, vem nos mostrar como o design se insere na formação identitária dessa tribo formada por rappers, dançarinos, DJs e grafiteiros. O coletivo Família de Rua, que reúne dezenas de jovens aos fins de semana, tem como objetivo promover lazer inserindo jovens marginalizados da sociedade, promover também ação social de inserção à cultura, a valorização da juventude e o direito de se apropriarem do espaço público para expressarem verbalmente e também simbolicamente sua condição social. Os veículos midiáticos serão os fomentadores dessa produção de cultura em massa. E o seu maior subsidiado é o design.

O design está inserido em suas roupas, artefatos, expressão gráfica (grafite) e nos modos que esses jovens interagem com esses artigos da indústria. $O$ design também está relacionado ao envolvimento emocional desses objetos com os seus integrantes e tudo o que eles simbolizam para a formação da identidade cultural do grupo. Nossa proposta, portanto, é analisar os instrumentos simbólicos manifestados pelo design, utilizados para caracterizar a identidade desse grupo.

\section{0 design e a cidade}

\subsection{O design como reflexo da cultura contemporânea}

No mundo contemporâneo, a globalização se faz predominante. A comunicação e o acesso às informações se tornaram cada vez menos distantes e de fácil acesso. Os meios midiáticos enchem suas páginas e telas de novos produtos a serem consumidos, e justificando a necessidade de se obter um determinado produto. O design como maior fomentador do consumo no mercado global, estimula também as interações intersociais.

O design vem construindo não só objetos e materiais para um uso objetivo e peremptório, mas ele vem embutido também de uma estrutura semiótica com uma carga subjetiva e abstrata. Assim, o modo como a sociedade se relaciona com esses objetos interferirá na cultura contemporânea provocando novos fenômenos comportamentais e gerando novas relações usuário-produto, produtousuário.

$\mathrm{O}$ design vem estabelecer a comunicação entre dois mundos. $\mathrm{O}$ mundo imaterial, subjetivo e simbólico cultural, e o material, aquele projetado e arquitetado pelos homens. Criando assim, uma ponte de informações, resinificando o modo de se fazer e de se entender um produto. Essa ressignificação muda através da bagagem cultural de cada sociedade e mesmo individual. 
Dentro dessas relações estabelecidas entre a sociedade, suas tecnologias e seus recursos naturais cabe destacar com mais ênfase as 'inter-relações culturais', pois neste momento de mediação, da transferência das ideias e das formas de pensar, do mundo virtual das possibilidades materiais e imateriais é que se estabelece culturalmente a ação do design de forma mais incisiva na sociedade. (FARIA e MOURA, 2008).

Essa interferência do design na sociedade provoca mudanças constantes na cultura e nas interações sociais existentes. A interatividade entre homem e os "objetos culturais" se dá através da percepção do mesmo no espaço permitindo sua troca de sensações e emoções com esses objetos, que acabam por promover um sentindo vital ao indivíduo. Essa vitalidade ocorre a partir do momento em que o usuário adere para a sua vida esses 'objetos culturais', e se reconhece nestes objetos, identificando-se e fazendo-se existir através deles.

Os 'objetos culturais' que existem no mundo, para entrarem em contato com o homem precisam de alguma maneira ser mediados, devem ser estabelecidas relações com o homem, a fim de que ambos se percebam presentes no mesmo mundo. A forma como os 'objetos culturais' existem ou são percebidos se deve a uma área de contato, que permite a troca de sensações e percepções. Existir implica se reconhecer no espaço e no tempo por meio do contato com o outro. (FARIA e MOURA, 2008).

A cidade representa uma estrutura, que é consolidada a partir de construções simbólicas e culturais. Os indivíduos que nela habitam interagem com os seus espaços de várias formas. O que irá definir as formas de uma cidade no seu aspecto global como na arquitetura e a cultura social, serão os grupos sociais que nela se dividem. A participação cultural varia de indivíduo para indivíduo. Cada um tem uma leitura e uma percepção diferenciada, ainda que inserido em um mesmo espaço. Em uma mesma cidade, podemos ter uma única cultura social vigente, porém com grupos que se subdividem, resultando em outras formas de cultura, transformando ainda mais os espaços da cidade.

\subsection{0 conceito de cultura}

A capacidade que o ser humano tem de gerar conhecimento, informações, símbolos e signos que tentam traduzir seu modo de pensar, existir ou até mesmo sobreviver vem desde os primórdios, onde a comunicação entre os seus se fazia imprescindível no dia-a-dia, como por exemplo, os desenhos em pedras de cavernas que já vinham sendo uma prática para a memorização e uma forma de se acumular conhecimentos, mesmo que de forma inconsciente.

A necessidade de se acumular conhecimentos para a sobrevivência em habitats que se mostravam cada vez mais hostis e o clima cada vez mais inconstantes, foi determinante para que hoje o homem pudesse adquirir todo esse aparato histórico e cultural.

$\mathrm{O}$ conceito de cultura foi definido pela primeira vez pelo antropólogo britânico Edward Burnett Tylor (1832-1917) que "tomado em seu amplo sentido etnográfico é este todo complexo que inclui conhecimentos, crenças, arte, moral, leis, costumes ou qualquer outra capacidade ou hábito adquiridos pelo homem como membro de uma sociedade." (TYLOR apud LARAIA, 1986, p. 25). Com este pensamento, o antropólogo define tudo aquilo que abrange ao comportamento do ser humano bem como a sua capacidade de acumular conhecimentos e exercitar a memória.

[...] ]em uma só palavra todas as possibilidades de realização humana, além de marcar fortemente o caráter de aprendizado da cultura em aquisição inata, transmitida por mecanismos biológicos" (LARAIA, 1986, p. 25).

A cultura é de um modo mais subjetivo, aquilo que acolhe um indivíduo, que o faça sentir-se vivo e aceito. É o fazer existir. Compartilhar com outros indivíduos as mesmas ideias e opiniões é uma nova identidade que toma forma. Um novo pensar com pessoas que se identificam, demonstrando nesse círculo, um processo de formação cultural.

Portanto, a cultura se insere de forma global dentro da sociedade desde a medicina, política, tecnologia, ciências, etc., até as artes, o folclore, as tradições, o lúdico, etc. 
Segundo Coll (2002), não existe um ato político que se desvincule da característica cultural de um país qualquer, por exemplo. Entanto, pode-se afirmar que a cultura encontra novas divergências de acordo com o seu interpretador. As transformações que ocorrem nela são diárias e infinitas.

Coll afirma que as diferenças culturais existem e é uma realidade a ser aceita e não superada. Essas mesmas diferenças geram um diálogo global que resultam em trocas de conhecimento, experiências e descobertas que impulsionam o processo evolutivo da humanidade.

O homem é o resultado do meio cultural em que foi socializado. Ele é um herdeiro de um longo processo acumulativo, que reflete o conhecimento e a experiência adquiridas pelas numerosas gerações que o antecederam. A manipulação adequada e criativa desse patrimônio cultural permite as inovações e as invenções. Estas não são, pois, o produto da ação isolada de um gênio, mas o resultado do esforço de toda uma comunidade. (LARAIA, 2013, p.45)

Para resumir, Laraia (2013) se baseia em Kroeber, antropólogo americano (1876-1960), que contribui na ampliação no conceito de cultura. A partir disso, Laraia escreveu os oito pontos seguintes:

1. A cultura, mais do que a herança genética, determina o comportamento do homem e justifica as suas realizações.

2. O homem age de acordo com os seus padrões culturais. Os seus instintos foram parcialmente anulados pelo longo processo evolutivo por que passou.

3. A cultura é o meio de adaptação aos diferentes ambientes ecológicos. Em vez de modificar para isto o seu aparato biológico, o homem modifica o seu equipamento superorgânico.

4. Em decorrência da afirmação anterior, o homem foi capaz de romper barreiras das diferenças ambientais e transformar toda a terra em seu hábitat.

5. Adquirindo cultura, o homem passou a depender muito mais do aprendizado do que a agir através de atitudes geneticamente determinadas.

6. Como já era do conhecimento da humanidade, desde o Iluminismo, é este processo de aprendizagem (socialização ou endoculturação, não importa o termo) que determina o seu comportamento e a sua capacidade artística ou profissional.

7. A cultura é um processo acumulativo, resultante de toda a experiência histórica das gerações anteriores. Este processo limita ou estimula a ação criativa do indivíduo.

8. Os gênios são indivíduos altamente inteligentes que têm a oportunidade de utilizar o conhecimento existente ao seu dispor, construído pelos participantes vivos e mortos de seu sistema cultural, e criar um novo objeto ou uma nova técnica. Nesta classificação podem ser incluídos os indivíduos que fizeram as primeiras invenções, tais como o primeiro homem que produziu o fogo através do atrito da madeira seca; ou o primeiro homem que fabricou a primeira máquina capaz de ampliar a força muscular, o arco e a flecha e etc. São eles gênios da mesma grandeza de Santos Dumont e Einstein. Sem as suas primeiras invenções ou descobertas, hoje consideradas modestas, não teriam ocorrido as demais. E pior do que isto, talvez nem mesmo a espécie humana teria chegado ao que é hoje.

Dessa forma, a cultura ocorre principalmente pela comunicação seja ela oral ou simbólica. Linguagens estas que se complementam mutuamente na construção de sentido para a comunidade, criando assim a cultura, fator singular que nos diferencia dos animais irracionais.

Entender a dinâmica cultural existente é de suma importância, já que assim previnem-se choques, preconceitos e imposições culturais. Saber que são estas diferenças que constroem a evolução do homem, seja na área da tecnologia, das ciências, das artes, da política, etc.

\subsection{0 design como agente de transformação das cidades}

As culturas urbanas tem sido um dos maiores agentes de modificação da cidade. Ela permeia entre a estetização e a realização pessoal de vida (o descobrimento da identidade e sua autoafirmação perante o outro). As múltiplas formas de manifestações culturais são consequência de vários fatores que juntos definem cada uma das culturas chamadas de tribos urbanas na cidade contemporânea. Classes sociais, classe etária e opiniões diferentes são só algumas formas de ilustrar o nascimento dessa cultura dinâmica em um mesmo espaço urbano. 
O espaço urbano não é somente o espaço de trabalho, de correria, de movimentação intensa. A cidade tem como função também de ter os seus espaços tomados como uma forma de o cidadão exercer esse direito, protestando, se expressando publicamente, não só criando uma identidade individual, mas como consequência, esses conjuntos de tribos culturais urbanas criam uma identidade para a cidade.

O design é articulado de várias formas para criar uma identidade. As principais formas de se fazê-lo são: através do design gráfico - slogans, cartazes, outdoors e etc. - através do design de produtos - mobiliário urbano em geral, artesanatos e etc. - através do design de moda - calçados, roupas, tecidos e etc. - através do design de ambientes - que se insere na conjuntura dos espaços formada pelo arquitetônico e pelo design de produtos, gráfico e moda.

Entanto, os movimentos culturais urbanos irão se apropriar dos espaços da cidade, dos artigos de indústrias e da moda da maneira que lhes convir, contextualizadas à suas maneiras de pensar e agir, provocando interferências. Como consequência disso, a criatividade será outro agente transformador da cidade. Essa criatividade é gerada principalmente pela diversidade étnica e social e pela democracia.

Todos os homens são designers. Tudo o que fazemos quase todo o tempo é design. O design é básico em todas as atividades humanas. Planejar e programar qualquer ato, visando a um fim específico, desejado e previsto, isto constitui um processo de design [...] design é compor um poema épico, executar um mural, pintar uma obra de arte, escrever um concerto. Mas design também é limpar e organizar uma escrivaninha, arrancar um dente quebrado, fazer uma torta de maçã, escolher os lados de um campo de futebol e educar uma criança. (BOMFIN apud JÚNIOR, 210, p. 402)

Nesse cenário urbano em que o design é inserido, as pessoas fazem deste espaço uma troca de comunicação, experiências socioculturais e lazer. O design está presente para então agregar valor a essas propostas culturais caracterizando assim, a cidade e o seu espaço urbano.

Uma forma de arte a ser assimilada em público e que representa sobretudo o próprio cidadão no espaço público parece ser uma das funções mais importantes da arte pública numa democracia. Muitos(as) artistas que enfrentam, esse desafio executam seu trabalho num campo experimental situado entre a participação ativa de parte da sociedade, colocações artísticas e documentação do real. Praticamente todos esses trabalhos estão como que à procura de uma oportunidade que lhes dê a chance de contribuir de maneira concreta à vida da sociedade, à vivência e à comunicação. As tentativas vão desde a abordagem direta de eventuais parceiros, passando pela elaboração artística das contribuições, até à oferta de participar da criação de novas estruturas de percepção (PALLAMIN apud JÚNIOR, 2010, p. 400).

\section{O movimento hip hop}

\subsection{A história do movimento}

$\mathrm{Na}$ década de 60 nos Estados Unidos, indivíduos negros e pobres eram fortemente marginalizados pela sociedade. Vivia-se um mal estar constante por parte dos negros. Um país que em seu discurso de Declaração da Independência dos Estados Unidos da América (1776) dizia que “... todos os homens são criados iguais, que são dotados pelo Criador de certos direitos inalienáveis, que entre estes são vida, liberdade e busca da felicidade." (Thomas Jefferson), vinha tendo profundos problemas com preconceitos raciais. Negros que se sentiam moralmente escravos dos brancos, vivendo em uma sociedade na qual raros eram os negros que conseguiam ascensão social. Os negros, que por consequência eram pobres, em sua grande maioria eram excluídos de uma boa escola, de praticar a cultura e lazer, de utilizar alguns meios de transportes e até mesmo sanitários públicos. 
Havia negros sendo presos por todo o país por qualquer motivo que fosse desde que fosse negro. A Ku Klux Klan (organização racista norte-americana) matava negros diariamente.

O mal estar social agravou-se. Movimentos sociais contra o preconceito racial e a luta pela dignidade negra, que já se faziam presentes, intensificam-se ainda mais com o assassinato de Martin Luther King Jr. em 1968, pastor batista, pregava a não-violência, pregava o amor e o diálogo interracial desde os anos 50 .

A música entra em cena como uma forma de protesto. Os guetos estavam infestados de manifestos socioculturais. A música para os americanos brancos da época destacava-se o rock’n roll, mas para os americanos negros era o soul. James Brown cantava "Say it loud: Im black and proud! We'd rather die on our feet than be livin' on our knees". (Diga alto: sou negro e orgulhoso! Nós preferimos morrer de pé, do que continuar a viver de joelhos. ).

Um pouco mais tarde, ainda na década de 60, surge o funk, um gênero mais agressivo que o soul, porém pregava as mesmas formas de protesto sociocultural e política.

O Hip Hop surge na década de 70, nas comunidades jamaicanas existentes na grande Nova Iorque. O rap, palavra formada pelas iniciais de rhythm and poetry (ritmo e poesia) fazia parte da cultura difundida como Hip Hop. Hip significa algo atual, que está acontecendo no momento e Hop refere-se ao movimento da dança.

Grandes caixas de som eram levadas para um bairro nova-iorquino, o Bronx onde residia em sua maioria negros. O DJ Kool Herc introduz a forma do canto rimado com letras politizadas, porém ao som de um reggae instrumental. E assim, com o uso de um mixer e dois discos idênticos ele repetia indefinidamente um mesmo pedaço da música, acompanhando as batidas da música e da rima. O MC (mestre de cerimônia) tem como função primordial organizar as batalhas de rima entre os rappers. As outras formas de manifestação cultural, como a dança, o grafite, o skate (a mais recente delas) foram surgindo aos poucos. A dança surgia de acordo com a necessidade de se acompanhar aquele novo ritmo, com breaks e mixagem. Já o grafite surge como outra forma de criarem uma identidade, de marcarem na "selva de concreto" aquilo que queriam, pensavam, sentiam, como forma de resistência social. Assim, a ideia era que todos os transeuntes que ali passassem, negros e brancos, pudessem ver que ali os negros, pobres e marginalizados, lutavam juntos através da música e da sua própria maneira de se fazer arte e lazer.

No Brasil o movimento Hip Hop chega em 1982, quando já havia jovens nos subúrbios dançando o break e fazendo rimas improvisadas. Muitos bailes de funk, soul e black music tomavam as cidades do Rio de Janeiro, São Paulo Salvador e Brasília. Esses eventos tinham como objetivo não só a prática de lazer, mas também representava para esse povo o orgulho negro e de resistência político-social. Assim como nos EUA, o movimento da música black aqui no Brasil, enfrentou muitas dificuldades também. Muitas batidas policiais, preconceitos sociais, pois a música black era considerada música de pretos, pobres e "vagabundos".

No Brasil, a origem do funk e do hip hop remonta aos anos 70, quando da proliferação dos chamados "bailes black" nas periferias dos grandes centros urbanos. Embalados pela black music americana, milhares de jovens encontravam nos bailes de finais de semana uma alternativa de lazer antes inexistente. Em cidades como Rio de Janeiro de São Paulo, formavam-se equipes de som que promoviam bailes onde foi-se disseminando um estilo que buscava uma valorização da cultura negra, tanto na música como nas roupas e nos penteados. (DAYRELL, 2005,p. 47)

Em Belo Horizonte o hip hop chega em meados dos anos 80, ainda pouco definido e chamado de funk, que hoje são duas vertentes da black music, bem diferentes, cada uma com suas peculiaridades. Este gênero ocupa as quadras de escolas públicas, os salões de dança da periferia, entre outros lugares que inicialmente tinham pouca visibilidade.

No final da década de 80 o funk e o rap começaram a assumir características mais singulares e definitivas. O funk com uma proposta de letras mais jocosas e brincalhonas e o rap apontava para denúncias sociais, descriminação e insatisfação político-social.

Os grupos de rap então procuram formar sua própria identidade, saindo dos espaços de bailes e assumindo lugares que consolidassem essa nova fase de transição e distinção do funk. A partir disso, o 
Hip Hop tomam as ruas, os viadutos, as praças das cidades. Tendo como principais referências da prática do Hip Hop em Belo Horizonte os bairros Venda Nova, Vilarinho e Centro.

Ainda hoje, o Hip Hop tem um papel social de suma importância para os seus adeptos, pois ainda é um discurso musical, com característica a ser um desabafo social, cultural e político. Desde então, a realidade no Brasil não é tão diferente quanto na década de 80. Problemas como pobreza, drogas, violência e preconceitos ainda são temas dos Duelos de MC`s em suas músicas.

\subsection{Movimento hip hop como afirmação da identidade de jovens}

Falar de jovens significa falar de descobertas, mudanças, diversidade e desafios. Essa heterogeneidade é concretizada nas diferenças de classes sociais, valores, etnias, religiosidade, regionalidade entre outras.

[...] ]em razão das diferentes origens de classe, que apontam para uma diversidade das formas de reprodução social e cultural. As culturas juvenis seriam sempre culturas de classe. Como produto das relações sociais antagônicas, expressariam sempre um significado político de resistência, ganhando e criando espaços culturais. (DAYRELL, 2005, p. 22)

A música, a cultura e a arte proporcionam aos jovens possibilidades de ascensão social dentro de suas periferias e muitas vezes fora delas, na sociedade. Comumente, esses jovens não têm dinheiro, emprego, nem acesso a uma educação de qualidade, mas quando são reconhecidos pelo seu talento seja este um bom cantor ou um exímio dançarino ou, ainda, um artista que faz o melhor grafite da cidade, sua autoestima perante a vida social muda. O que se tem percebido atualmente é cada vez mais o assolamento das classes desfavorecidas, tirando delas o direito à dignidade, ao lazer e à convivência social. E a música insere-se neste contexto como é um agente transformador, que vem permitindo aos jovens se libertarem de suas frustrações e dificuldades.

É evidente que a instituição escolar apresenta dificuldades em respoder às demandas que lhe são colocadas, com mecanismos perversos intra/extra - escolares que terminam excluindo grande parte da população juvenil dos direitos educativos. (Sposito, 1999) Assim como no trabalho, para essa parcela da população a escola parece não constituir uma referência de valores na sua construção como sujeitos. A situação dessas parcelas de jovens se agrava, ainda, na esfera pública, pelo encolhimento do Estado, que não oferece soluções por meio de políticas que comtemplem a juventude, o que gera privatização e despolitização das condições de vida. (DAYRELL, 2005, p.23)

O hip hop tem assumido um papel nas periferias não só de liberdade de expressão e rompedor de estigmas sociais, mas também com um papel de conscientizador/educador para esses jovens. Muitas letras falam sobre o mundo das drogas, que estas não levam a lugar nenhum, que a violência gera violência e reforça que o jovem tem que ir à luta com honestidade para conseguir o que é seu por direito.

Segundo Dayrell (2005), as músicas escritas por esses jovens concretizam a existência dos mesmos. As letras falam por si mesmas. Todos os conflitos diários em meio à cidade, às periferias, às angústias que o assolam são todas descritas de forma a compartilhar com outros que se sintam da mesma forma, que se identifiquem sobre a mesma situação.

\subsection{A estética do movimento}

A moda do hip hop teve várias origens, como a afro-americana, latina e caribenha. No início, as roupas eram mais justas, como calças de tecido jeans e camisas de algodão, e bem coloridas. $\mathrm{O}$ uso de bonés e muitos adereços também já eram marcantes. Com o tempo, principalmente os dançarinos do movimento hip hop, foram percebendo que eram necessárias roupas mais largas, para que no momento 
da dança ficasse mais confortável realizando os movimentos no ritmo da música. Os MCs também sentiram essa necessidade para se expressar melhor nos seus movimentos perante o público. Portanto, o tecido dessas roupas também mudaram.

O primeiro estilista a traduzir a moda convencional com o estilo do Hip Hop foi Karl Kani (1968), que desenvolveu as primeiras calças com o formato propriamente largo. Pelo sucesso das vendas, ele recebeu o título de "The Godfather of fashion Urban" .

A base do estilo da moda atualmente são roupas esportivas como moletons e calças de nylon, contendo ainda referências de suas raízes africanas, latinas e caribenhas. Além disso, há diversos adereços, como correntes de metal, brincos e anéis como parte do estilo. O tênis é, geralmente, confortável para as performances na dança e entres outras expressões corporais.

Com a globalização, várias influências e modificações transformam diariamente esse estilo da cultura popular de rua. Como, por exemplo, a mistura de outros estilos de origem moderna, clássica, elegante, entre outros.

\section{O manifesto: hip hop do Viaduto de Santa Tereza}

\subsection{O hip hop do coletivo Família de Rua}

A partir da ocupação dos espaços da cidade de Belo Horizonte por movimentos socioculturais, jovens se reúnem para fazer música, dançar, se libertar de estigmas sociais e sentirem-se livres naquele espaço do qual se identificam.

O nosso objeto de pesquisa tratou, portanto, do coletivo Família de Rua, um grupo que ocupa o espaço situado debaixo do Viaduto de Santa Tereza na Avenida Assis ChateuAubriand em frente ao número 809, aos domingos por volta das 14:00 horas. O coletivo é formado por Pedro Valentim (PDR), Thiago Antônio (Monge), Leonardo Lucas (Ozléo), Ludmila Ribeiro e Rafael Lacerda, todos com idades entre 30 a 40 anos. O grupo que além de cantar suas próprias autorias, abrem espaço para que os meninos e meninas da comunidade possam fazer o mesmo nos eventos, disponibilizando todo material de som e áudio. Além de administrar os momentos de pausa para as outras artes da rua, como o esporte praticado pelos skatistas e as coreografias praticada pelos dançarinos.

O Duelo de MCs surge na Praça da Estação, em agosto de 2007, há quase 10 anos, e se desloca para o Viaduto de Santa Tereza, no final do ano. Consolidou-se, então, no viaduto no início de 2008. $\mathrm{Na}$ Praça da Estação, o coletivo Família de Rua ainda não tinha um nome e nem uma identidade definida. A partir da repercussão do movimento e das demandas que foram surgindo, foi necessário criar um nome e fortalecer uma identidade que transparecesse o ideal pelo qual acreditavam e a causa que eles abraçavam.

O coletivo interrompeu suas apresentações durante cinco meses no ano de 2013 , tendo como motivos: o excesso de uso de drogas por parte dos usuários do espaço e a necessidade de "... repensar a forma ou as formas de ocupar aquele espaço. Foi quando entendemos que era hora de mudar e decidimos começar um novo movimento nas tardes de domingo", afirma Pedro Valentim, integrante do coletivo Família de Rua.

O local se apresenta cheio em dias de evento. As pessoas ali presentes são tanto de classe média baixa como também o espaço é tomado por pessoas de classe média a alta. Isso pode ser observado através das roupas e acessórios de marca dos quais esses jovens utilizam. Portanto, a mistura das classes sociais acontecem muito naturalmente dentro do espaço do viaduto e é dinâmico, qualquer um que se identifique com o movimento se sente à vontade para se aproximar.

O Mestre de Cerimônia, Pedro Valentim, cumprimenta as pessoas que estão ali para ver o movimento do hip hop acontecer. Este tem como papel de organizar o Duelo e entreter e conversar com os participantes. Dois participantes da batalha de Duelo de Mc's sobem ao palco. O intermediador os apresenta. O som é ligado na caixa e a improvisação das frases por cada participante no ritmo da música começa. As pessoas deliram de alegria a cada frase bem rimada, a cada protesto bem colocado.

No momento do Duelo parece haver uma rivalidade entre os participantes da batalha, porém quando tudo acaba, eles se cumprimentam e se abraçam. Tudo é muito pacífico e humano. Mesmo que 
só um deles ganhe a batalha, os dois saem felizes do palco. Percebe-se nisso algo de motivador e satisfatório em estar ali para cantar o que vem à mente, os seus versos e passar a sua mensagem. Não é uma competição. É uma forma de conscientizar, talvez, aqueles que estão ali para ouvi-los. "Quando estou no palco é tudo muito espontâneo. Nada nos atinge. É como se fosse um esporte. Quando o jogo acabou, fica tudo tranquilo." Diz F.P., de 17 anos, estudante e participante das batalhas de MCs.

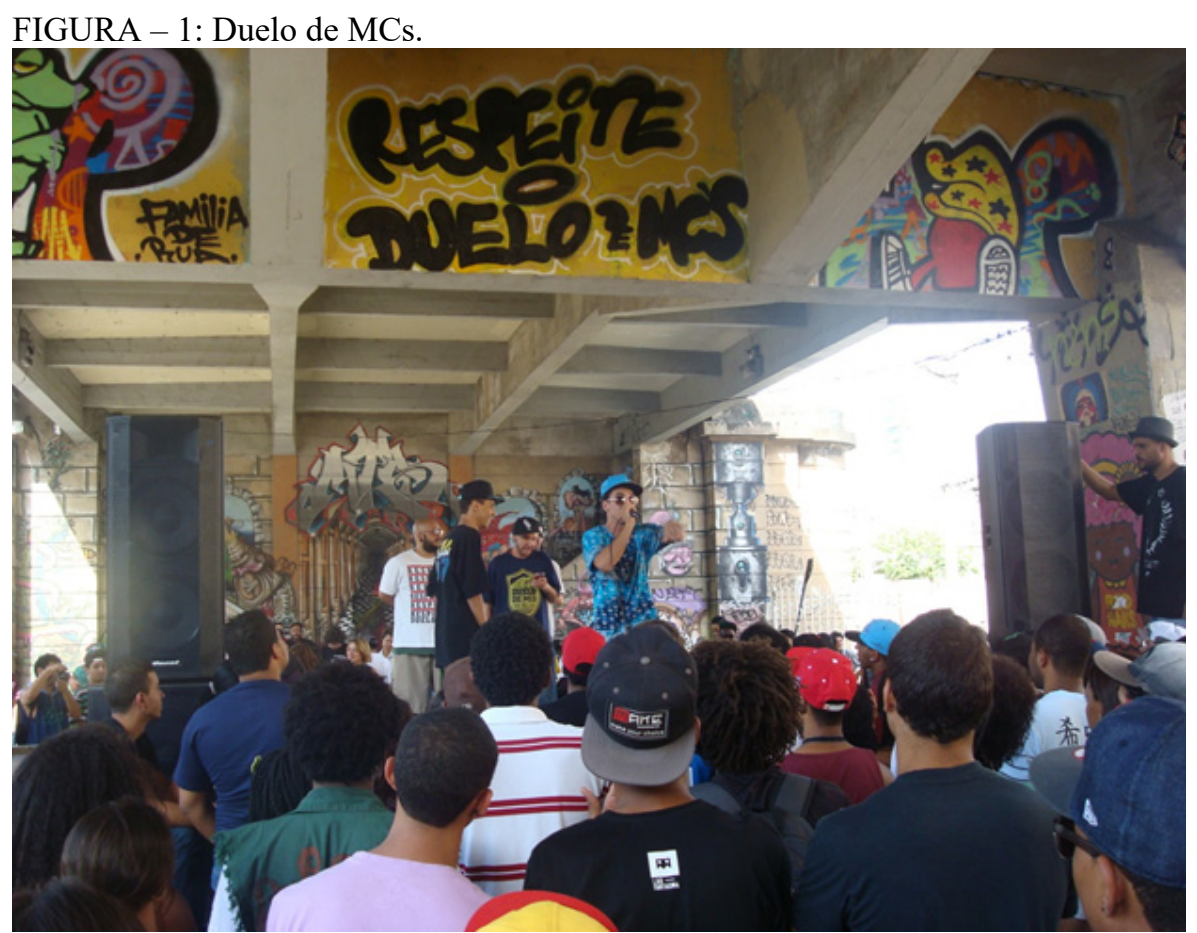

Fonte: CERQUEIRA, 2013.

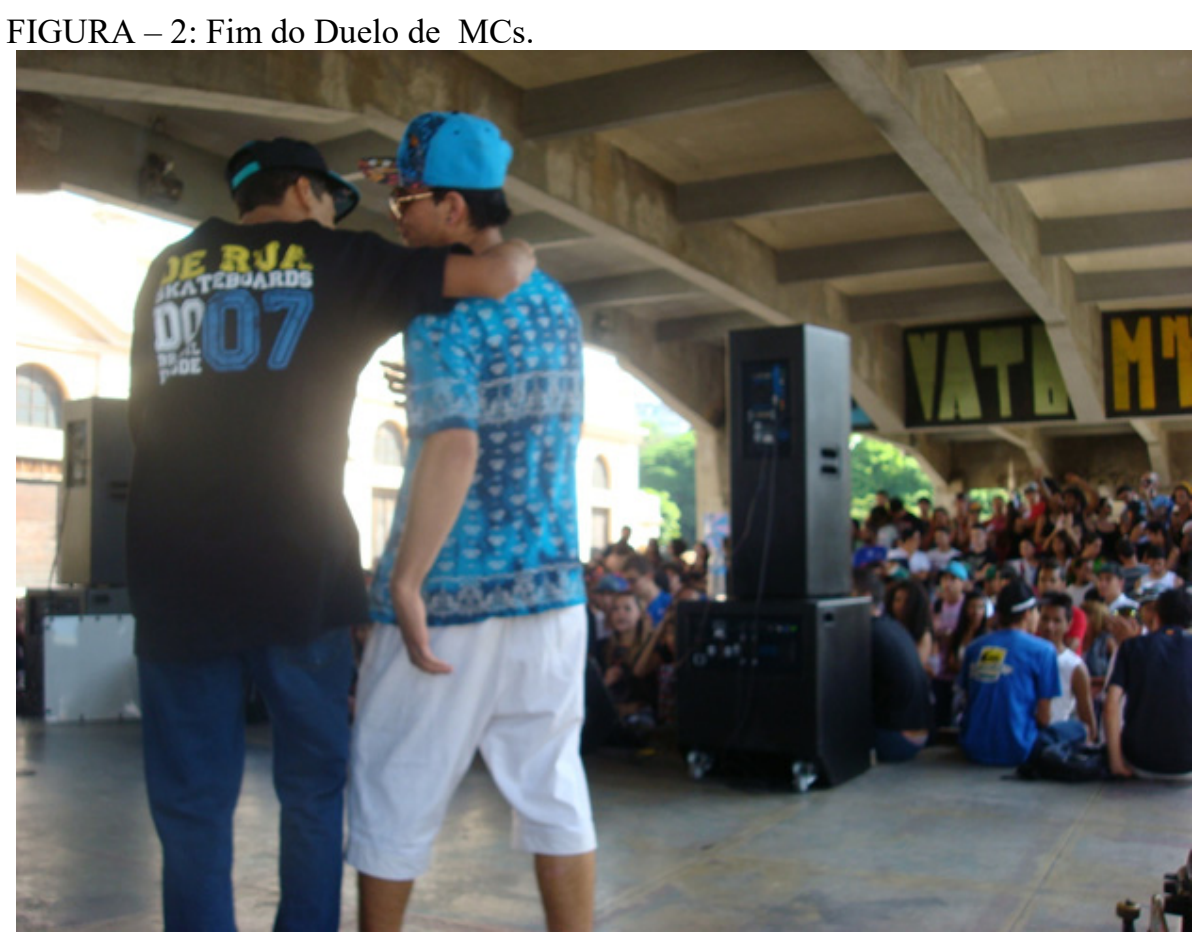

Fonte: CERQUEIRA, 2013.

Quando o Duelo acaba. O intermediador, ou o Mestre de cerimônia, pede para todos abrirem uma roda. Todas se afastam da pista central e ficam em volta. O som começa a tocar. Um rapaz entra na pista e começa a dançar, apresenta as suas coreografias e acrobacias com um sorriso no rosto. Uma 
dança complexa, com muitos movimentos. Quando um sai da roda, outro entra e faz a sua coreografia acontecer. E assim por diante. Em torno de cinco a sete dançarinos se apresentam. Os jovens ali observam atentos aos passos, aos movimentos, estimulando os dançarinos com palmas e elogios.

FIGURA - 3: Dança hip hop.

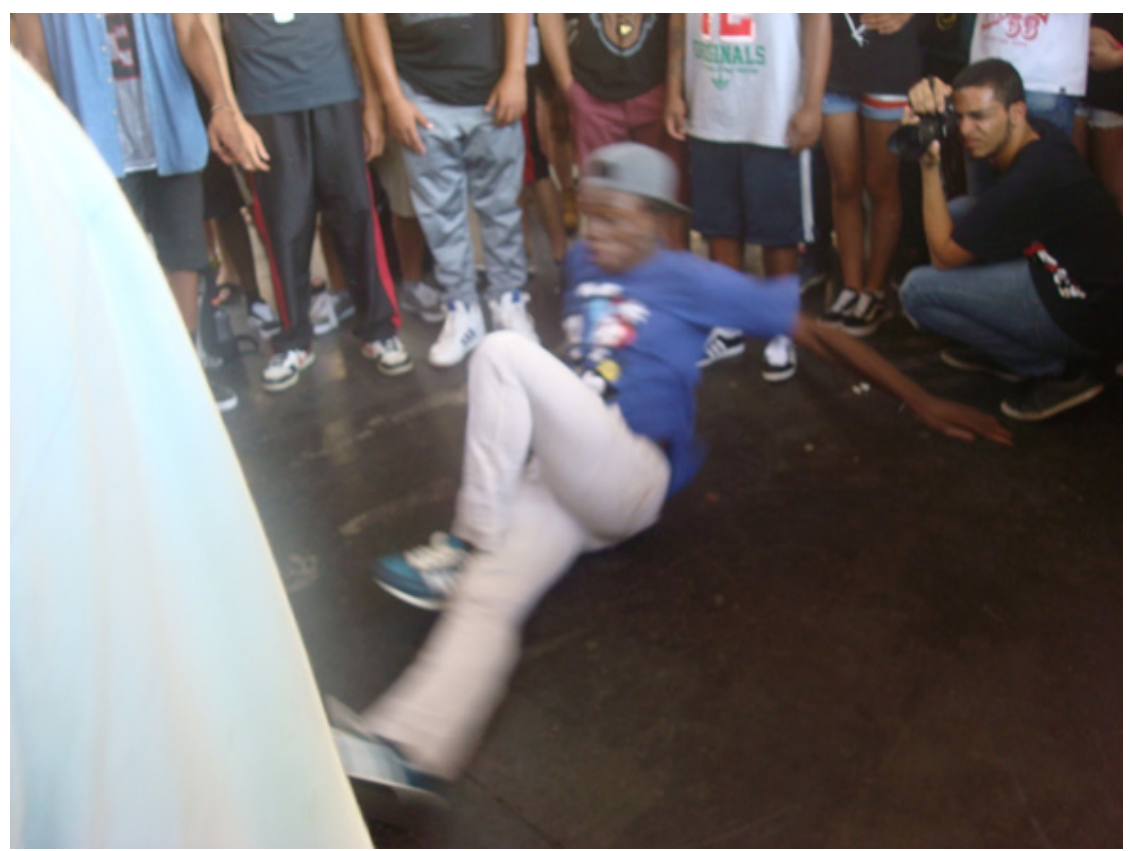

Fonte: CERQUEIRA, 2013.

FIGURA - 4: Roda de dança.

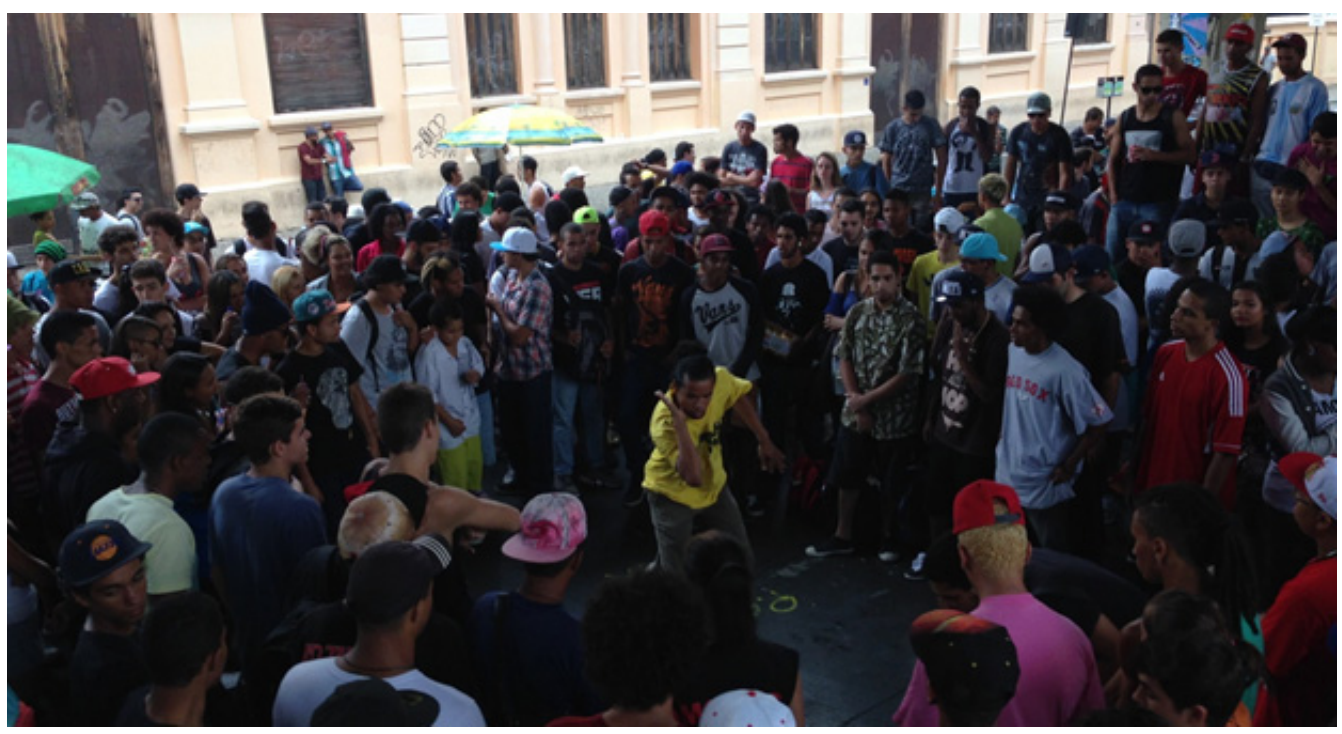

Fonte: CERQUEIRA, 2013.

Há sempre a presença de policiais no evento e, de vez em quando, interferem retirando algum "baderneiro" ou usuário de drogas.

A FDR sempre se propôs a dialogar com todas as instâncias do poder público que passam pelos projetos que realizamos na cidade. Mas nunca conseguimos avançar muito na relação com a polícia. E já tivemos duas situações complicadas em 2010 e 
2011, quando a PM-MG realizou ações grandiosas no Duelo com a presença da mídia tradicional (Record e Globo), na tentativa de incriminar o Duelo de MCs. Mas eles não foram bem sucedidos. (PDR, 2014).

No Duelo, há espaço para todos que quiserem ir. Atualmente, o espaço é frequentado por muito jovens negros e brancos também. Meninas também tem seu direito a participar das batalhas de MCs. No hip hop do coletivo Família de Rua, os preconceitos e as rixas pessoais entre gangues são desencorajados pelos integrantes. Ali, percebemos a construção de um lugar de convivência, de compartilhar com as outras pessoas experiências, desabafos e insatisfações.

Além disso, há o comércio de camisetas, bottons e bonés do coletivo, com o intuito de divulgar essa manifestação como sociocultural de grande valor para a periferia mineira e criar a identidade do grupo. Há outros comércios também, como bazar de roupas usadas, revista artística, vendas de alimentos e bebidas alcoólicas e não alcoólicas.

Portanto, o design se insere nas divulgações do coletivo seja nas mídias sociais com slogans, peças gráficas, a própria marca do projeto que contribui para a identidade visual de todo o movimento.

FIGURA - 5: Comércio ambulante.

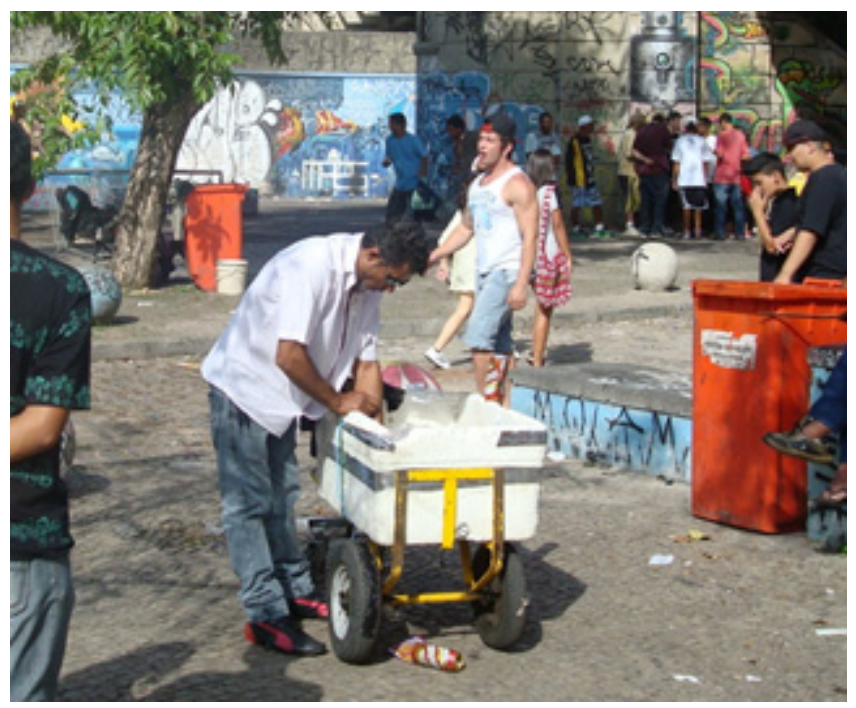

Fonte: CERQUEIRA, 2013.

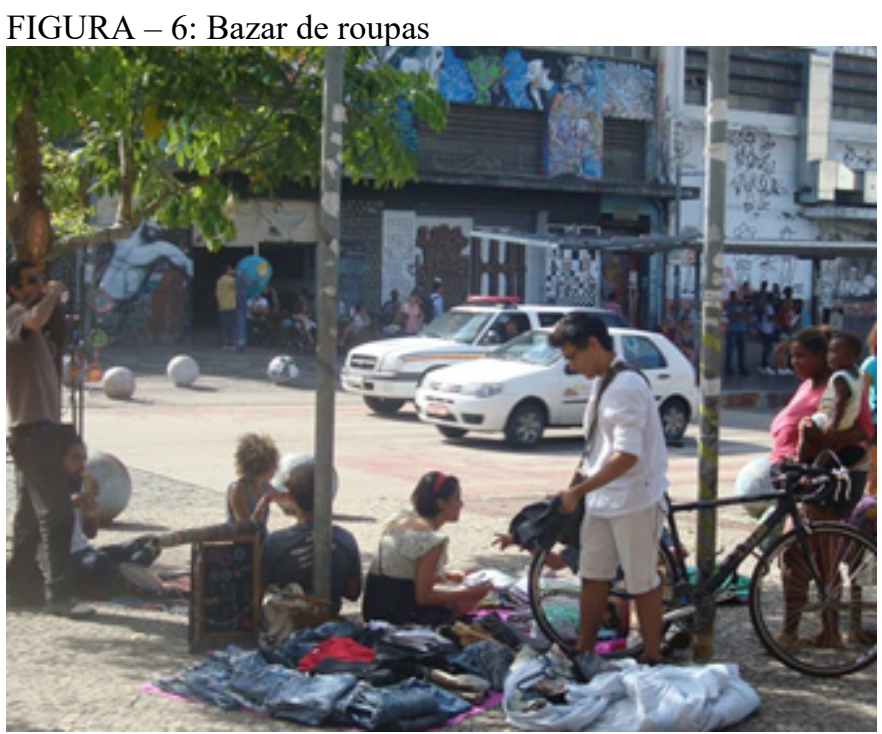

Fonte: CERQUEIRA, 2013. 
FIGURA - 7: Marca Família de Rua.

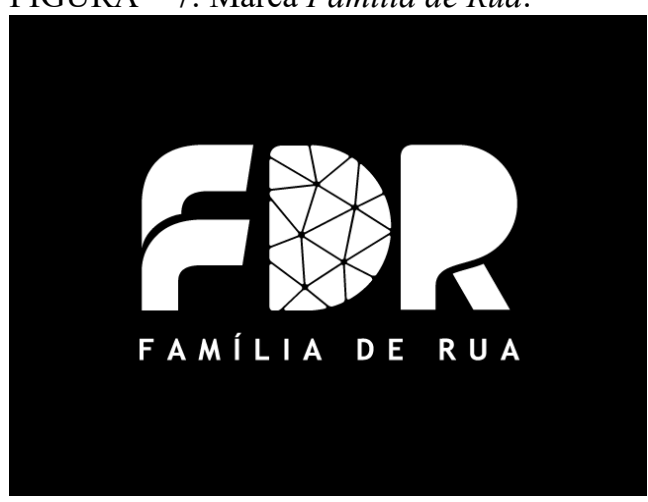

Fonte: https://www.facebook.com/familiadrua

FIGURA - 8: Camisas e bonés na loja virtual do coletivo.

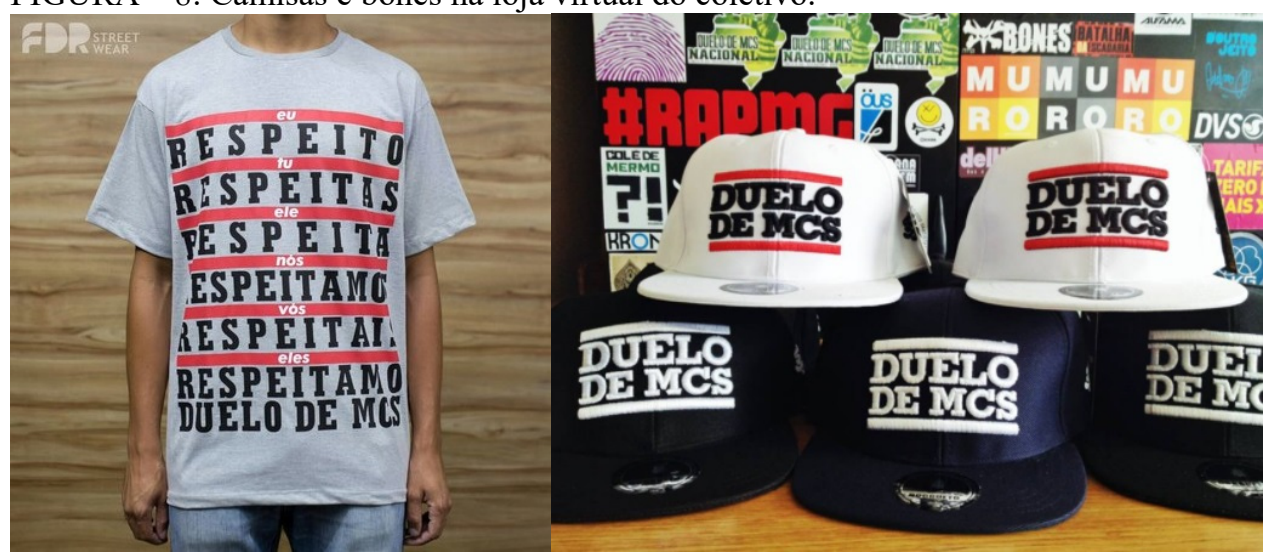

Fonte: https://www.familiaderua.com.br/

FIGURA - 8: Cartaz de divulgação nas mídias sociais pelo ilustrador Estevam Gomes.

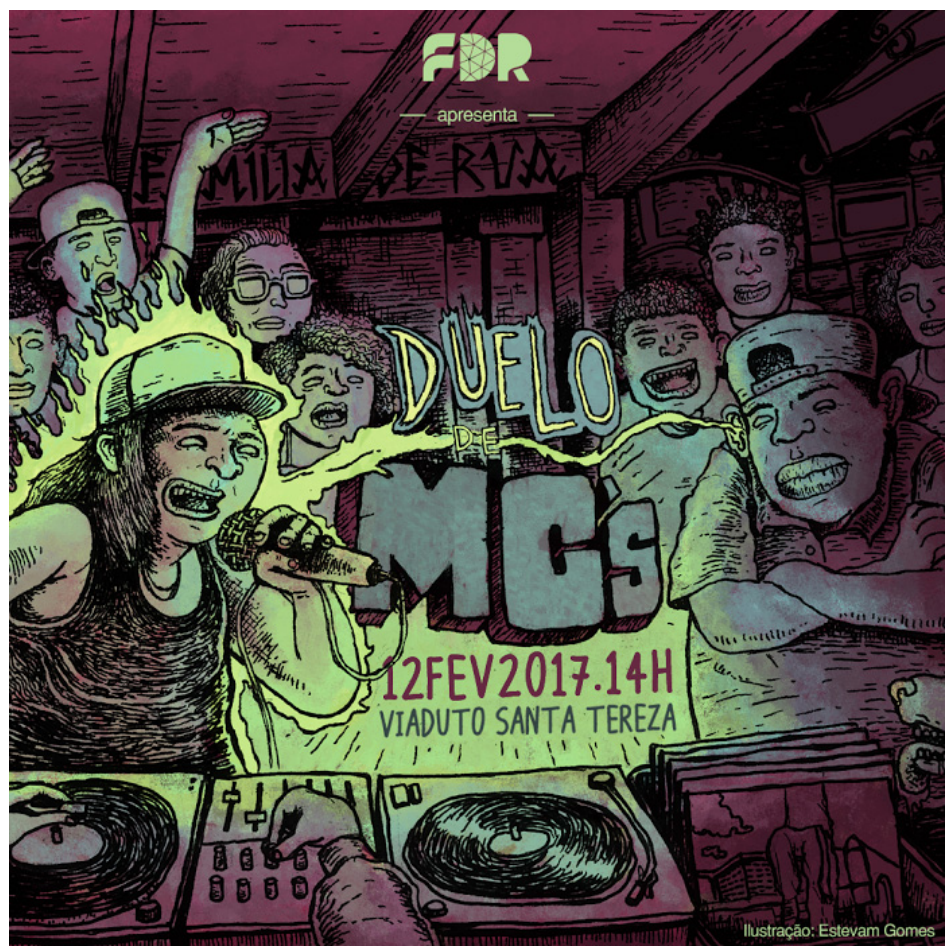

Fonte: https://www.facebook.com/familiadrua 
No dia 24 de setembro de 2013, havia uma faixa escrita com os seguintes dizeres: "Eu existo!". Nota-se, a partir disso, que as pessoas que frequentam aquele espaço têm completa consciência da sua marginalização perante a sociedade. Nem todos que ali frequentam são/estão marginalizados, como já dissemos, há pessoas de classe média alta que frequentam o espaço. Contudo, essas pessoas que frequentam o viaduto compartilham desse sentimento. No Viaduto você "existe". Tudo é possível. Todos ali são iguais e estão unidos pela música e pelas suas letras de desabafo social, pela dança, por toda uma cultura jovem que muitas vezes é repudiada pela sociedade.

FIGURA - 7: Faixa "Eu Existo" no Viaduto de Santa Tereza.

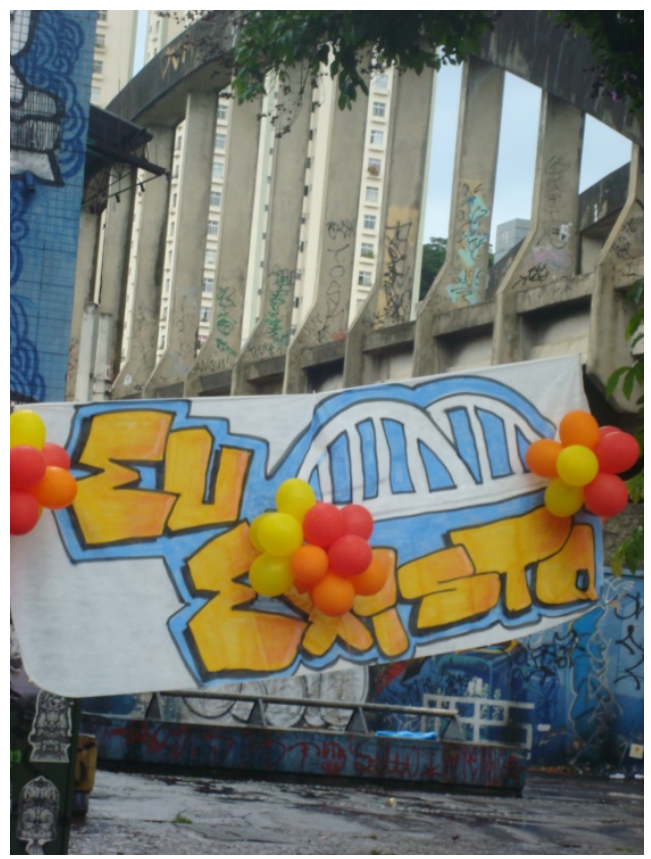

Fonte: CERQUEIRA, 2013.

O Hip Hop é quem nos fez ser quem somos. Através dele, aprendemos a entender a complexidade do outro e respeitá-lo. E aquilo que aprendemos vivenciando essa cultura tentamos compartilhar com quem vem depois da gente, pra que essas informações também sirvam de referência, como foi pra nós. (PDR, 2014).

Atualmente, o coletivo Família de Rua é uma das maiores referências da cultura urbana brasileira. Ainda se apresentam nos domingos a tarde provendo outras ações comunitárias como doações de roupas e tênis para os jovens. Essas doações são principalmente para os jovens que praticam o skate que muitas vezes ficam sem condições para comprar novos tênis.

E em comemoração aos 10 anos, o coletivo Família de Rua lança o disco, "Ontem, hoje e sempre" que reflete a história do movimento, das raízes musicais das quais são inspiradas em ritmos brasileiros, como Clube da Esquina e sons de berimbau. Melodia que misturam referências da música black, como o jazz e o soul, com o auxílio de saxofones e bateria. Letras diretas sobre suas vivências e a realidade das lutas socioculturais diárias.

\section{UMA DÉCADA OCUPANDO AS RUAS}

A Família de Rua é um grupo formado por amigos que acreditam na essência da cultura e das manifestações artísticas urbanas. Para tanto, trabalha focado na promoção da cultura hip hop e do skate em seus moldes originais, preservando a originalidade e a força presentes na arte e no estilo de vida daqueles que respiram a rua cotidianamente. O coletivo é fruto do "Duelo de MCs", que, ao lado do "Família de Rua Game of Skate", são seus principais projetos do grupo. 
O investimento da Família de Rua desde o ano de 2007, com o "Duelo de MCs", evento de destaque no cenário Hip Hop nacional que acontece periodicamente em Belo Horizonte, fez o Hip Hop de Minas Gerais ir além de Belo Horizonte, ao mesmo tempo em que trouxe o Hip Hop de todo o Brasil para o Viaduto Santa Tereza, na capital mineira. (Família de Rua, 2017) ${ }^{1}$

\section{Considerações finais}

Nota-se que os movimentos socioculturais são uma forma de inserir o jovem e exercer o seu direito ao lazer, a liberdade de expressão, motiva-lo ao convívio social e elevar a sua autoestima diante dessa sociedade que tanto o marginaliza.

O design não só interfere na forma como os jovens do hip hop no Viaduto de Santa Tereza se apresentam nas roupas, acessórios e artigos da indústria, mas na forma como eles interagem entre si. Como eles acreditam naquela forma de se expressar. Podemos perceber, portanto, a assunção de uma postura revolucionária e transgressora. Eles não querem somente ser ouvidos. Querem ser vistos por toda a sociedade que os marginaliza. A maioria das pessoas que estão lá para ouvi-los compartilha desse mesmo sentimento. Criando, assim, uma identidade, apropriando-se de um espaço urbano, se caracterizam no mesmo modo de se vestir, de falar e pensar, fazendo delas um grupo cultural dentro de Belo Horizonte. A rua se torna para eles um lugar em que se preza pelo respeito à alteridade, onde compartilham um sentimento de pertença, através de noções simbólico-culturais, que, como pudemos apurar, são materializadas pelo e no design. A rua é, pois, uma segunda casa onde todos ali, juntos, formam uma família.

\section{The Semiotics of Design: The Construction of Identity in Young People of Hip Hop in the Santa Tereza Viaduct.}

Abstract: The present study aimed to investigate the symbolic aspects of design and its influences inserted in urban hip hop culture. Analyze how these youngsters, mostly low-middle-class blacks, use industry articles to affirm themselves to society and strengthen their identities. Thus, a more in-depth study was required in sociocultural manifestations such as urban cultures, youth identity, forms of occupation of the city, research on black music culture and its emergence. Understand how design can be a powerful tool in the transmission and promotion of cultural manifestos. Bring a reflection of how individuals appropriate spaces and objects and how they are part of them and their socio-cultural existence. The object of study for this research was the manifesto of the collective Familia de Rua. Familia de Rua is a group of young rappers who hold meetings on Sunday afternoons at the Viaduto de Santa Tereza in Belo Horizonte. They provide interaction, leisure and cultural promotion for young people, mostly from the periphery. Through the songs of protest and political nature, they envisage enriching discussions for the young people present. There were also interviews with participants of the movement so that we could have a global vision of the movement and the true meaning of music, and the aesthetic symbols that permeate the movement in the lives of these young people.

Keywords: design; hip hop; urban cultures.

\footnotetext{
${ }^{1}$ Disponível em: http://www.diadamusica.com.br/familiaderua
} 


\section{Referências bibliográficas}

COLL, Augustí Nicolau. Propostas para uma diversidade cultural intercultural na era da globalização. Coleção: Cadernos de proposições para o século XXI. São Paulo, Instituto Pólis, 2002. 124p.

DAYRELL, Juarez. A música entra em cena: o rap e o funk na socialização da juventude. Belo Horizonte. Editora UFMG, 2005. 303p.

FARIA, José Neto. MOURA, Mônica. Design e cultura contemporânea: a formação dos objetos culturais. São Paulo, 3, 14 p., maio de 2008. Disponível em: http://wright.ava.ufsc.br/ alice/conahpa/anais/2008/conahpa2008.zip\%20Folder/artigos/Design_e_cu Itura_contemporanea_a_formacao_dos_objetos_culturais.pdf. Acesso em: 24 de jan., 2014.

JÚNIOR, Ary Scapin. Design cênico: técnica, processo \& criação na identidade urbana. Design, Arte, Moda e Tecnologia. São Paulo: Rosari, Universidade Anhembi Morumbi, PUC-Rio e Unesp-Bauru, 2010, p. 400. Disponível em: http://sitios.anhembi.br/damt6/arquivos/43.pdf.

LARAIA, Roque de Barros. Cultura um conceito antropológico. Rio de Janeiro: Zahar, 1986. 108 p.

MORAES, Dijon. Design e multiculturalismo. In: MORAES, Dijon; (orgs.). Cadernos de estudos avançados em Design: multiculturalismo. 2a edição. Vol.1. Belo Horizonte: UEMG, 2013. 11-14 p.

PIMENTEL, Spensy. 0 Livro Vermelho do Hip-Hop. Disponível em: http://www.literarua.com.br/morto/gratuito/OLivroVermelhodoHipHop.PDF. Acesso em: 12 de março de 2014.

Família de Rua. Disponível em: http://www.diadamusica.com.br/familiaderua. Acesso em: 20 de jun., 2017. 